\title{
ALCOHOLIC INTOXICATION;
}

IS IT AN EXCLUSIVELY MALE AFFAIR?

Dr. Nasim llyas, Dr. Kashif Rahim, Dr. Saleem Murtaza, Dr. Sidrah Nadeem.

ABSTRACT......Objective: To assess the epidemiology of Alcohol consumption in Tehsil Hassan Abdal, district Attock, Punjab, Pakistan. Material and Method: The Medico legal cases record from 2009 - 2011 were studied for alcohol cases at Civil Hospital Hassan Abdal. Results: In the selected medico legal cases alcohol consumption was surprisingly reported only in male gender. Conclusion: The involvement of younger males in alcohol consumption was found to be predominant. The trend of alcohol consumption was noted among both urban as well as rural population, with more urban cases as compared to rural.

\section{Key words: Alcohol, medico legal cases (MLC).}

Article Citation

Ilyas N, Rahim K, Murtaza S, Nadeem S. Alcoholic intoxication; Is it an exclusively male affair? Professional Med J 2013:20(5): 840-845.

\section{INTRODUCTION}

Alcohol is considered to be more than just a drink, a number of harmful social and health hazards are associated with its intake beside a few beneficial effects $^{5}$. Alcoholism is a syndrome, resulting in deterioration of health, in ability to perform mental activity and failure in handling personal and social responsibilities ${ }^{8}$.

Approximately 02 billion people consume alcoholic beverage worldwide according to WHO report 2004, alcohol related disorders mounts to 76.3 million. The following are alcohol related harmful effects, esophageal cancer, liver cancer, cirrhosis of the liver, homicide, epileptic seizures and road traffic accidents, burns, poisonings, falls and drowning ${ }^{13,15-18}$. With consumption of Alcohol, dependence occurs and ability to abstain from Alcohol becomes out of control ${ }^{6}$. Destruction of family as intimate partner violence is much higher among alcoholics as compared to nonalcoholic general population. Alcohol intake during pregnancy poses higher risk of complications to pregnant lady as well as to the fetus ${ }^{9,12,20}$.

Alcohol is considered to be more than just a drink. A number of harmful social and health hazards are associated with its intake beside a few beneficial effects. Alcoholism is a syndrome, resulting in deterioration of health, in ability to perform mental activity and failure in handling personal and social responsibilities. Aggressive behavior and road traffic accidents were associated with alcohol consumption $^{10,20,22}$. Higher incidence of sudden deaths among Alcoholics as compared to general population. Rapid increase since 1970 in alcohol related deaths, in UK 40,000 deaths per year. Sudden deaths were blamed due to arrhythmias due to alcohol intake. Loss of population due to alcohol related deaths in countries like Sweden ${ }^{4,21}$.

Islamic jurisprudence specifies which foods are halal

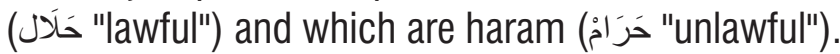
This is derived from commandments found in the Qur'an, the holy book of [Islam], as well as the Hadith and Sunnah, libraries cataloguing things the Prophet Mohammed is reported to have said and done.In Islam, alcoholic beverages—or any intoxicant-are generally forbidden in the Qur'an through several separate verses revealed at different times over a period of years. At first, it was forbidden for Muslims to attend to prayers while intoxicated ${ }^{1,2}$.

Present study was carried out to assess the prevalence of alcohol intake in the tehsil Hassan Abdal. Hassan Abdal is $48 \mathrm{~km}$ from Rawalpindi. Tehsil Hassanabdal is one of the six Tehsils of district Attock. 
It spreads over an area of 350 square kilometres with a population of 135,856 (as per DCR 1998).It is located where the Grand Trunk Road meets the Karakoram Highway near the North-West Frontier Province. It is $40 \mathrm{~km}$ northwest of Rawalpindi2 ${ }^{23}$.

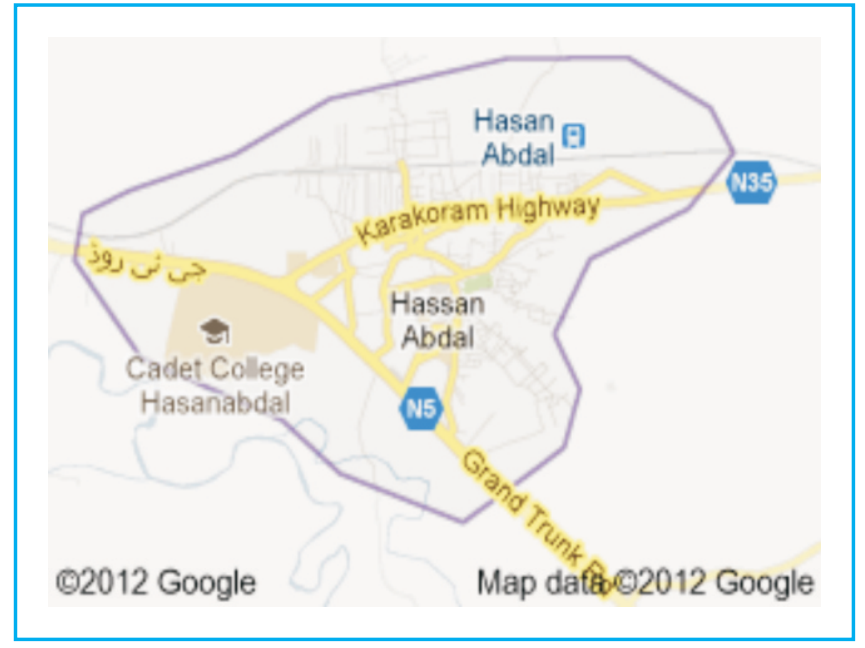

In Tehsil Hassan Abdal, Tehsil Headquarter hospital is the only center for the examination of medico legalcases from both urban and rural areas. There is separate record room, where record of medico legal is kept under the supervision of record keeper and no unauthorized person is allowed.

\section{MATERIAL AND METHOD}

\section{Setting:}

Medico legal cases record from 2009 - 2011 were studied for assessment of prevalence of alcohol consumption at Civil Hospital Hassan Abdal.

\section{Design:}

Medico legal record was selected from 2009 - 2011 and alcohol cases were screened.

\section{Sample Size:}

A total of 58 cases were reported from 2009 - 2011, selected for the study.

\section{Procedural Steps:}

For the access to the medico legal cases record, submission of the request to the Head of institution, to MS Civil Hospital Hassan Abdal, Punjab, Pakistan, was made.

\section{Recording of data:}

The data was recorded on specialized data collection forms, prepared prior to the initiation of the study.

\section{RESULTS}

Table-I shows the total number of Alcohol cases reported between the years 2009 - 2011. Table-I also shows that all the alcohol cases were reported in male gender only.

Table-Il shows that alcohol was prevalent in both urban and rural male population between the years 2009 2011. Table-Il also shows that alcohol is much more prevalent in urban males as compared to rural males in the three periods from 2009 to 2011.

Table-III shows the record of cases in both urban and rural male alcohol cases of 2009 - 2011. It shows the yearly variation of reported cases from 2009 to 2011. Highest cases were reported in the year 2010, followed by 2009 and 2011. In year 2009 and 2010 urban male cases of alcohol were predominant as compared to rural male cases. In year 2011 more rural male cases reported as compared to urban male cases of alcohol.

Table-IV shows the record of cases in the different age groups, with highest number of cases in the age (years) 21 to 30 . No case reported in the age group (years) $0-10,61-70$ and $\& 71+$.

\begin{tabular}{|c|c|c|}
\hline \multicolumn{3}{|c|}{ Population Characteristics } \\
\hline Gender & No. of cases & Percentage \\
\hline Males & 58 & $100 \%$ \\
\hline Females & 00 & $0 \%$ \\
\hline Total cases & 58 & $100 \%$ \\
\hline \multicolumn{2}{|c|}{ Table-I. Medico legal cases (Alcohol) $2009-2011$}
\end{tabular}




\begin{tabular}{|c|c|c|c|c|c|}
\hline \multirow{2}{*}{$\begin{array}{c}\text { Population characteristics } \\
\text { Residence }\end{array}$} & \multicolumn{3}{|c|}{ Years } & \multirow{2}{*}{ Total cases } & \multirow{2}{*}{ Percentage } \\
\hline & 2009 & 2010 & 2011 & & \\
\hline Urban Male & 07 & 22 & 03 & 32 & $55 \%$ \\
\hline Rural Male & 04 & 11 & 08 & 23 & $40 \%$ \\
\hline Residence Not Mentioned & 01 & 02 & 00 & 03 & $5 \%$ \\
\hline Total Cases & 12 & 35 & 11 & 58 & $100 \%$ \\
\hline
\end{tabular}

\begin{tabular}{|c|c|c|c|c|c|}
\hline Population characteristics & \multicolumn{5}{|c|}{ Years } \\
\hline Age groups & $\mathbf{2 0 0 9}$ & $\mathbf{2 0 1 0}$ & $\mathbf{2 0 1 1}$ & Total cases & Percentage \\
\hline $0-10$ & 0 & 0 & 0 & 0 & $0 \%$ \\
\hline $11-20$ & 3 & 0 & 2 & 5 & $8.6 \%$ \\
\hline $21-30$ & 6 & 20 & 5 & 31 & $53.4 \%$ \\
\hline $31-40$ & 2 & 5 & 3 & 10 & $17.2 \%$ \\
\hline $41-50$ & 0 & 5 & 1 & 6 & $10.3 \%$ \\
\hline $51-60$ & 1 & 0 & 0 & 1 & $0 \%$ \\
\hline $61-70$ & 0 & 0 & 0 & 0 & $0 \%$ \\
\hline $71+$ & 0 & 0 & 0 & 0 & $8.6 \%$ \\
\hline N.A age group & Nil & 5 & Nil & 5 & $100 \%$ \\
\hline Total cases & 12 & 35 & 11 & 58 & \\
\hline
\end{tabular}

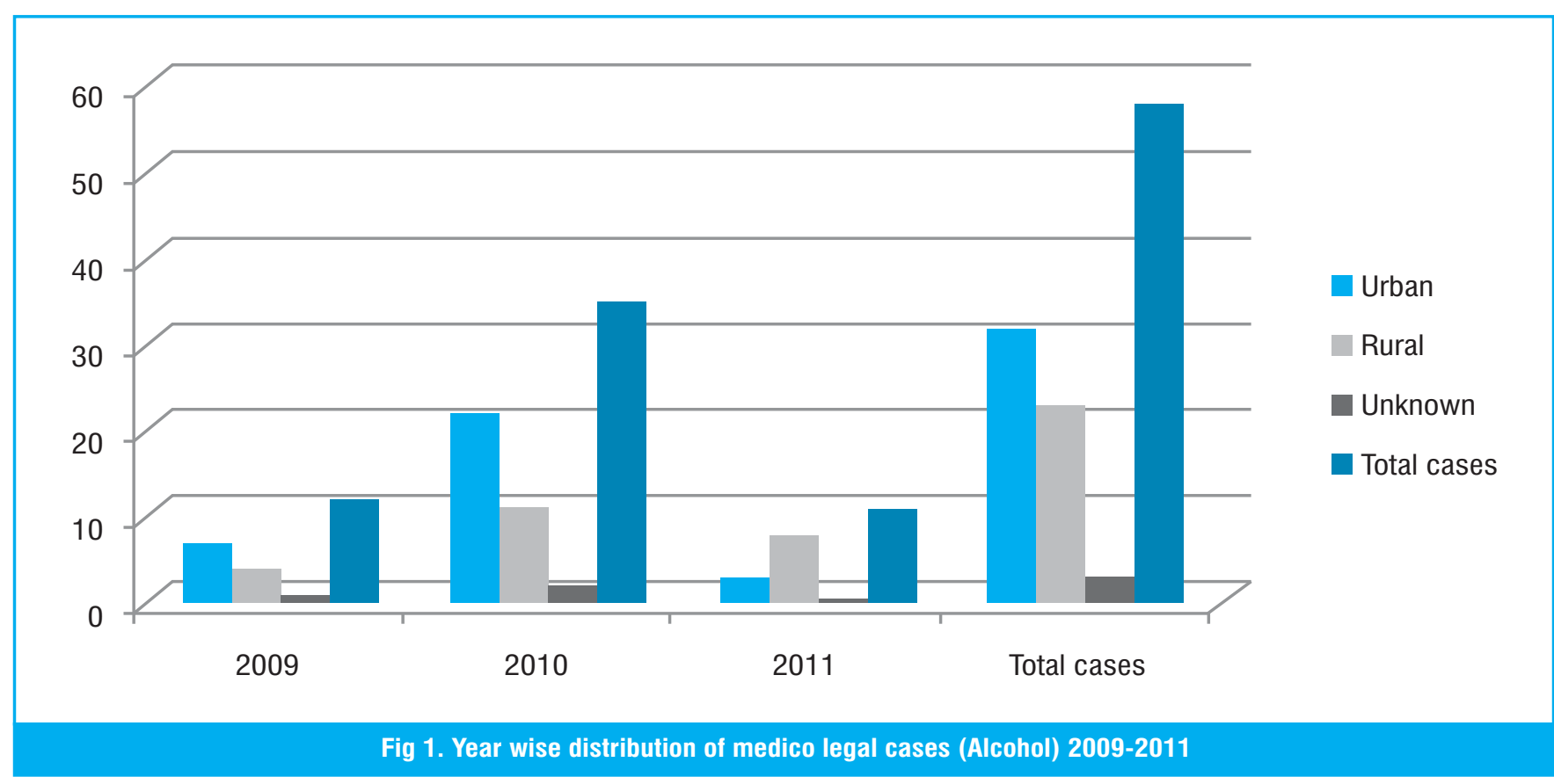




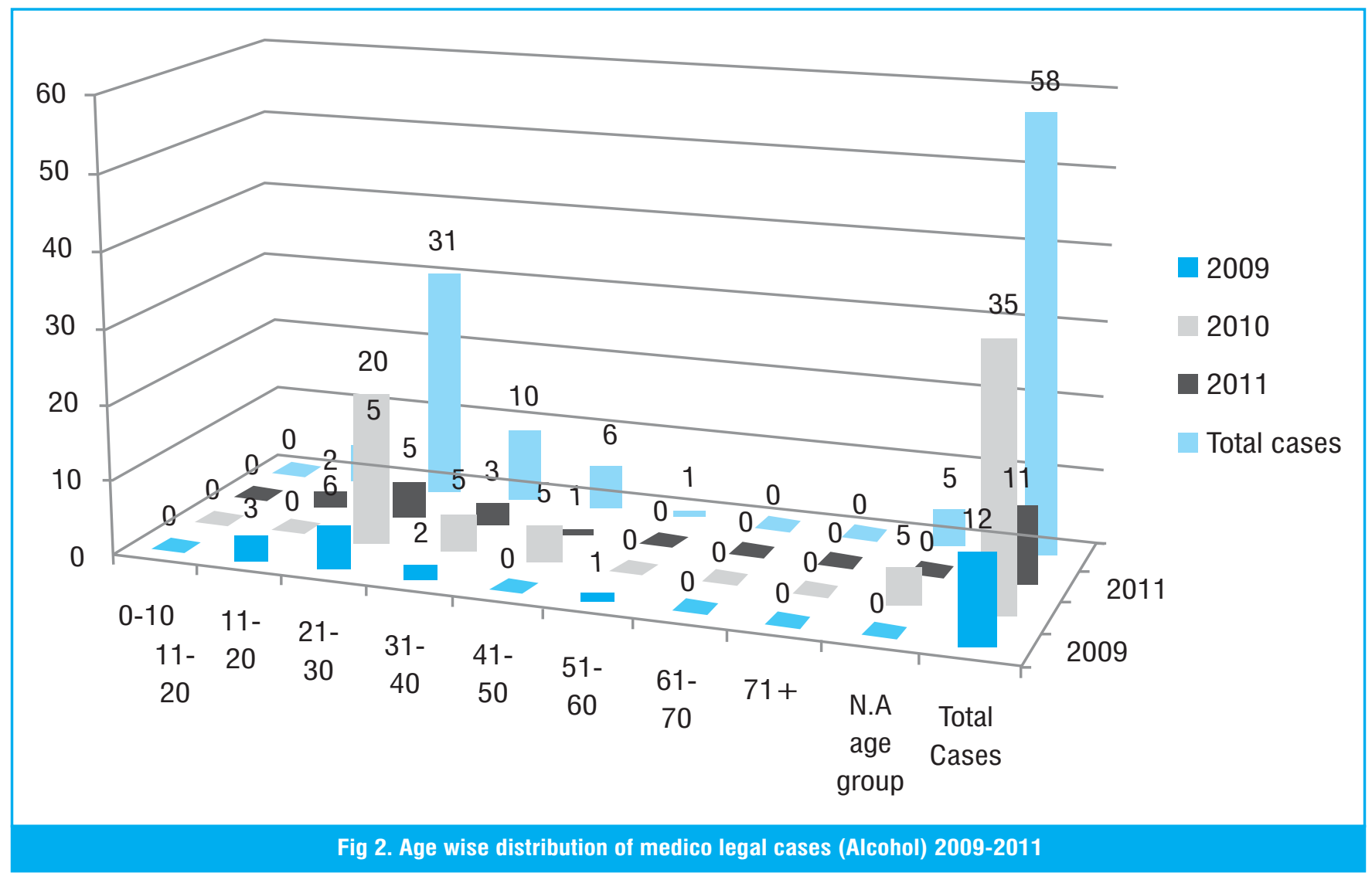

\section{DISCUSSION}

The present study was conducted in the Tehsil Hassan Abdal District Attock to assess the prevalence of the alcoholism. This study is first of its kind to be conducted in the same area.Most of the people have the perception that alcoholism is not an issue in Pakistan and especially in backward areas. The reason for the perception is because of the fact that alcohol intake is prohibited in Islam as well as under Pakistani law $^{3}$.

The present study reveals that between the years 2009 - 2011, all the alcohol cases were reported in male gender only. Alcohol was much more prevalent in urban males as compared to rural males. There was yearly variation of reported cases, Highest in the year 2010, followed by 2009 and 2011. The younger population found to be more involved with alcohol intake, with highest number of cases in the age 21 to
30 (years), these results were comparable with similar previous studies $^{6,7,14}$.

It has been shown in a previous study that there are several other countries having comprehensive prohibition against the alcohol consumption, e.g;

- Afghanistan

- Brunei

- India (only Gujarat, ban on sale)

- Iran

- Kuwait

- Libya

- Saudi Arabia

- Sudan

- UAE (only Sharjah)

- Yemen

- Pakistan $_{6}$

The WHO report on the Alcohol consumption shows 
higher percentage of alcohol abstainers among the adult population in the countries with majority Muslim population and lower percentage in western countries.

\begin{tabular}{|c|c|c|c|}
\hline Country & Total \% & Male \% & Female \% \\
\hline Australia & 17.5 & 14.1 & 20.8 \\
\hline UK & 12 & 9 & 14 \\
\hline Greece & 8 & 1 & 15 \\
\hline USA & 33.9 & 29.3 & 38.2 \\
\hline Egypt & 99.5 & 99 & 100 \\
\hline Syria & 95.7 & 92.4 & 98.8 \\
\hline Saudi Arabia & 97 & 95 & 99 \\
\hline Pakistan & 94.5 & 90 & 99 \\
\hline
\end{tabular}

\section{CONCLUSION AND FUTURE RECOMIMENDATIONS}

The involvement of younger males in alcohol consumption was found to be predominant. The trend of alcohol consumption was noted among both urban as well as rural population, with more urban cases as compared to rural.

- Strict and efficient implementation of laws

- Awareness campaign to be launched regarding hazards of drinking

- Provision of alcohol breathe analyzer

- Psychological counseling for alcoholics

- Refresher course for Medico legal officers

- Special training to Police for detection of Alcohol intoxication suspect

Copyright@ 24 May, 2013.

\section{REFERENCES}

1. The Noble Qur'an - al-Baqarah 2:219, - An-Nisa, ayat 43.

2. Hadith - Abu Dawood, Narrated Umar ibn al-Khattab.

3. The Prohibition (Enforcement of Hadd) Order, 1979.

4. Smith G.S, Branas CC. Miller T.R. Fatal Non-traffic injuries involving alcohol: A Meta-analysis. Ann
Emerg Med. 1999 Jun;33(6):659-68

5. Rehm J., Gmel G., Sepos C.T., Trevisan M. Alcoholrelatedmorbidity and mortality. Alcohol Health2003; 27 (1): 39-51.

6. Alcohol per capita consumption, patterns of drinking and abstention worldwide after 1995. Appendix 2. European Addiction Research, 2001, 7(3):155-157.

7. Kokotailo PK. Alcohol use by youth and adolescents: a pediatric concern. Pediatrics. 2010 May; 125(5): 1078-87.

8. Mathurin $P$ and Deltenre P. Effect of binge drinking on the liver: an alarming public health issue? Gut 2009; 58:613-617.

9. Bradley KA, Badrinath S, Bush K, Boyd-Wickizer J, Anawalt B. Medical risks for women who drink alcohol. Journal of General Internal Medicine. 1998;13:627-639

10. Tanaka N, Asada T, Kinoshita T, Yamashita F, Uno M. Alcohol consumption and risk of dementia. Lancet. 2002;360:491

11. U.S. Department of Health and Human Services, Public Health Service, National Institutes of Health, and the National Institute on Alcohol Abuse and Alcoholism. Underlying Mechanisms of Alcohol-Induced Damage to the Fetus. 10th Special Report to the U.S. Congress on Alcohol and Health, Chapter 5, Prenatal Exposure to Alcohol; Jun, 2002. pp. 300-322.

12. Jones KL, Smith DW, Ulleland CN, Streissguth P. Pattern of malformation in offspring of chronic alcoholic mothers. Lancet. 1973; 1:1267-71.

13. Makelä P, Paljärvi T, Poikolainen K. Heavy and nonheavy drinking occasions, all-cause and cardiovascular mortality and hospitalizations: a follow-up study in a population with a low consumption level.J Stud Alc ohol. 2005; 66: 722-728.

14. Haider W and Aslam M. Prevalence of Alcoholism inthe Punjab, Pakistan. Biomedica Vol.24, Jul. - Dec. 
2008/Bio-25.

15. Klatsky AL. Alcohol, cardiovascular diseases and diabetes mellitus. Pharmacol Res. 2007; 55: 237-247.

16. Baan R, Straif K, Grosse Y, Secretan B, El Ghissassi F, Bouvard V, Altieri A, Cogliano V. Carcinogenicity of alcoholic beverages. Lancet Oncol. 2007;8:292-293

17. Corrao G, Bagnardi V, Zambon A, La Vecchia C. A metaanalysis of alcohol consumption and the risk of 15 diseases. Prev Med. 2004; 38:613-619.

18. Moskal A, Norat T, Ferrari P, Riboli E. Alcohol intake and colorectal cancer risk: a dose-response metaanalysis of published cohort studies. Into $\mathrm{J}$ Cancer. 2007; 120:664-671.

19. Cherpitel CJ, Borges GL, Wilcox HC. Acute alcohol use and suicidal behavior: a review of the literature. Alcoholism: Clinical and Experimental Research. 2004; 28:18-28. 2004.

20. Dube, S.R., Anda, R.F., Felitti, V.J., Croft, J.B., Edwards, V.J., Giles, W.H., 2001. Growing up with parental alcohol abuse: exposure to childhood abuse, neglect, and household dysfunction. Child Abuse Negl. 25, 1627-1640.

21. National Institute on Alcohol Abuse and Alcoholism (NIAAA), 2007. National Epidemiologic Survey on Alcohol and Related Conditions (NESARC). National Institute on Alcohol Abuse and Alcoholism. $<$ http://www.niaaa.census.gov/> (retrieved December 20, 2007).

22. Nantulya MV, Reich MR. The neglected epidemic: Road traffic injuries in developing countries. BMJ. 2002;324:1139-41

23. http://www.tmahassanabdal.com/

24. http://www.who.int/substance_abuse/publications/ globalstatusreportalcohol2004_drinkpatterns.pdf

Correspondence Address:

Dr. Nasim llyas

Civil Hospital, Hassanabad.

biochemistry.Imct@gmail.com
1. DR. NASIM ILYAS

Civil Hospital, Hasanabad.

2. DR. KASHIF RAHIM

Department of Biochemistry RIHS, Islamabad.

3. DR. SALEEM MURTAZA

Department of Pharmacology IIDC, Islamabad.

4. Dr. Sidrah Nadeem
Article received on: 14/02/2013 Accepted for Publication: 24/05/2013 Received after proof reading: 19/09/2013

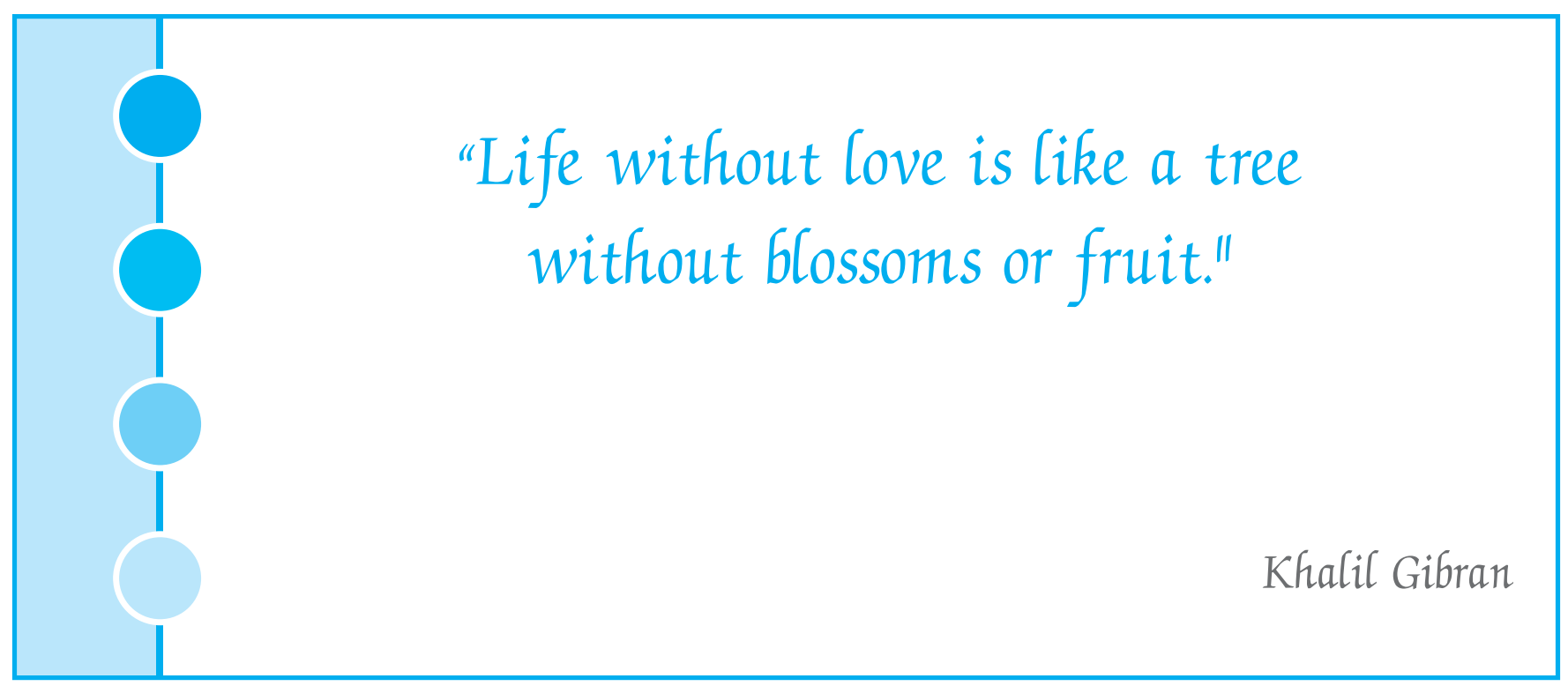

